\title{
O Suicídio - reavaliando um clássico da literatura sociológica do século XIX
}

\author{
Durkheim's Suicide: reassessment of a classic from \\ 19th-century sociological literature
}

Everardo Duarte Nunes 1

\footnotetext{
1 Departamento de Medicina Preventiva e Social, Faculdade de Ciências Médicas, Universidade Estadual de Campinas. Cidade Universitária "Zeferino Vaz", Campinas, SP 13081-970, Brasil.
}

A bstract This paper presents a detailed review of Suicide, the sociological classic by Durkheim, 100 years after it was first published. The first part of the article focuses on the author's interest in the theme, within the scope of concerns on the importance of studying suicide dating from the 18th century. The article then presents a circumstantial review of the various chapters, preceded by bri ef remarks on the book's place within Durkheim's work as a whole. The third part of the article comments on the book with reference to the main authors that have studied it. Amongst other qualities, the book's importance lies in the fact that it associates an elaborate theoretical construction with the empirical data, working within the possibilities provided by late 19th-century moral statistics. The article stresses Durkhei m's perspecti ve of dealing with the impact of the macrostructures over micro-level phenomena. The distribution of suicides is also reviewed, updating information and the relationship between suicides and professional groups, for example. The paper also provides a critique of authors who stress the importance of "meanings" in the analysis of suicides, with some notes on the relationship between suici de and mental disease. Key words Sociology; Suicide; Social Behavior; Death

Resumo Na marca dos cem anos da publicação de O Suicídio, é realizada uma revisão detalhada dessa obra de Durkheim, clássi co da literatura sociológi ca. Na primeira parte do artigo são considerados os moti vos que teriam levado o autor a interessar-se pelo tema, dentro das preocupações que, desde o século XVIII, situaram a importância do estudo do suicídio. Em seguida, a obra érevisada de forma circunstanciada, consi derando todos os seus capítulos. Esta parte é precedida por rápidas considerações sobre a colocação desse clássi co no conjunto da produção do autor, até a data da sua publicação, 1897. Na terceira parte do artigo, são feitos os comentários sobre a obra, recorrendo-se aos princi pais autores que a estudaram. Sobressai, entre outros aspectos, a importância desse trabal ho, que associa elaborada construção teórica aos dados empíricos, trabalhando dentro das possi bilidades que as estatísticas morais ofereciam no final do sé culo XIX. Salienta-se a perspectiva de Durkheim de tratar o impacto das macroestruturas sobre os fenômenos de nível mi cro. Revisa-se, também, a distribui ção dos suicídios, atualizando-sealgumas informações e as rel ações que se evi denciam entre, por exemplo, suicídi os e grupos profissionais. Introduz-se, ainda, a crítica de autores quesalientam a importância dos 'si gnificados' na anál ise dos suicídios e al gumas anotações sobre a rel ação suicí di os/doença mental .

Palavras-chave Sociologia; Suicídio; Comportamento Social; Morte 
“Eu interrompi minhas conferências para devotar-me compl etamente ao livro que estou preparando sobre O Suicídio. Eu espero que quando ele apareça as pessoas terão uma melhor compreensão da reali dade do fenômeno social sobre o qual el as não concordam comigo, porqueo queaí eu estudo éa disposição social para o suicídio (le courant social au suicide), a tendência dos grupos sociais para o suicídio, isolada de suas manifestações individuais (por abstração certamente, porque a ciência não isola seu obj eto de nenhuma outra maneira)." Durkheim em carta para Bouglé, datada de 16 de maio de 1896 (Lukes, 1977:193).

\section{O suicídio como tema de estudo}

“Era 3a feira, 6 de julho (1886), cerca de 8 horas da manhã, ele estava aprontando-se para sair para o liceu. Ele estava ... saindo quando, rapidamente mudando de idéia, ele disse: 'Eu devo pronunciar uma palestra, porém não estou suficientemente preparado. Eu devo subir outra vez e olhar novamente minhas anotações'. Ele entrou em sua sala, no segundo andar, tomou seu livro deanotações e sentou-se na beirada de uma janela muito baixa sem parapeito, quefacilmente induzia à vertigem. Elefez um rápido e imprudente movimento, característico dele, e perdeu o equilíbrio. Poucos mi nutos depois ele estava caído no pátio interno, seu livro de notas ao seu lado." (Durkheim, 1887, apud Lukes, 1977:51).

Foi dessa forma que Émile Durkheim registrou a morte de um de seus mais íntimos e queridos amigos - Victor Hommay - no necrológio que a ele dedicou, publicado no L'annuaire de l'association des anciens élèves de l'École Supérieure, em 1887. Ao relatá-la, Durkheim (1887, apud Lukes, 1977:51) descreve-a como “um miserável etrági co acidente", mas, como é visto por muitos estudiosos, entre eles Lukes (1977), a morte de Hommay não foi um acidente; ele, em verdade, cometeu suicídio.

Não se trata aqui de detalhar a personalidade - triste e solitária - e as dificuldades de Hommay, que poderiam ter potencializado o seu desejo de morrer, e sim de lembrar que Durkheim ficou profundamente abalado pela morte trágica de seu amigo. Lukes (1977:191), ao reconstituir os motivos que teriam levado Durkheim a se dedicar ao tema do suicídio, salientou que essa morte "com certeza afetou-o profundamente pode muito bem ter influenciado não somente seu interesse pelo assunto, mas também a sua expli cação, pelo menos em sua forma 'egoística'”. Há, como salienta este analista da obra do sociólogo francês, outros motivos menos pessoais. Em realidade, quando Durkheim (1982) publica, em 1897, O Suicídio: Estudo Sociológico, ele já havia dedicado ao tema um artigo, datado de 1888 , sobre as relações entre suicídio e natalidade, e o terceiro curso de sociologia por ele ministrado, em 1889-1890, teve o suicídio como tema central.

Acompanhando os pontos básicos levantados por Lukes (1977), referentes aos motivos que podem explicar esse interesse pelo suicídio, além de inscrever-se em suas idéias sobre as funções morais da família, verifica-se que muitos deles são inerentes a uma preocupação mais geral sobre o tema, assim como refletem uma preocupação que foi específica do projeto sociológico que Durkheim perseguia.

1) Desde o século XVIII o suicídio vinha sendo estudado como um problema moral, para, no século XIX, ser visto como um "crescente problema social a exi gir explicação", nas palavras de Lukes (1977), que retoma as análises feitas por Douglas (1970). Segundo este autor, o estudo estatístico do suicídio foi entendido pelos pesquisadores e teóricos como um estudo da moralidade, incluindo-o na categoria geral das estatísticas morais, junto com outros eventos como assassinato e outros crimes. "Assumia-se", segundo Douglas (1970:8), “que o suicídi o era um problema moral eimplicitamentequequalquer teoria sobre o suicídio deveria incluir os aspectos morais do sui cídio como um dos fatores bási cos". O acúmulo de informações estatísticas proporcionou, de outro lado, que se estabelecessem inúmeras correlações, juntamente com o levantamento de hipóteses. Estas irão relacionar taxas diferenciais de suicídio a fatores sociais, tais como: ocupação, urbanização, religião, mudança social, como também a fatores não sociais: hereditariedade, raça, clima e a questão não resolvida - se o suicídio era ou não relacionado à desordem mental. No mais, nas palavras de Lukes (1977:192): “Havia também uma concordância geral que aceitava quea escalada das taxas gl obais de suicídi os eram devidas à passagem da ordem tradicional a uma nova ordem eao crescimento do industrialismo". 2) O suicídio parecia aos investigadores um objeto concreto e específico, "particularmente adequado", como escreve Durkheim (1970:37). Além disso, estava associado diretamente não somente a várias instituições, como a família, mas à sociedade como um todo.

3) Para Durkheim, o tema propiciava a possibilidade ímpar de poder demonstrar os princípios por ele estabelecidos em seu tratado metodológico, escrito em 1895, As Regras do Método Sociológico. 
4) O tema oferecia a Durkheim a possibilidade de ilustrar uma das formas pelas quais se manifestava a malai se geral que afetava a Europa, sugerindo, inclusive, os remédios para vencê-la.

5) Para o sociólogo francês, constituía um exemplo suficientemente significante para estabelecer a compreensão científica da sociologia como uma disciplina independente. Explicar sociologicamente um evento individual que parecia depender quase exclusi vamente de fatores pessoais, psicológicos, mas que expressava uma forma de dissolução dos laços que unem os homens, possibilitava entender quais os laços que os levam a se associarem.

Como tão bem sintetiza Douglas (1970), foi com base em uma longa tradição do pensamento europeu sobre o suicídio que Durkheim desenvolveu o seu trabalho: a ênfase sobre o caráter imoral do suicídio, a utilização das fontes estatísticas como um instrumento básico, a importância dos fatores extra-individuais na regularidade das taxas de suicídio. De outro lado, não pode ser minimizado o esforço desenvolvido por Durkheim a fim de elaborar um modelo que integrasse a teoria e os dados, não somente sistematizando al gumas das preocupações anteriores, mas colocando o objeto de estudo numa perspectiva que ressaltasse a sua maneira de interpretar a sociedade dentro de um referencial que tinha a dissolução social como questão básica.

\section{A obra}

O Suicídi o foi publicado pela primeira vez em 1897, quando Durkheim tinha 39 anos de idade ejá havia escrito dois trabalhos fundamentais em sua carreira de pesquisador: as duas teses de doutorado, que datam de 1893 - Dela Division du Travail Social: Étude sur l'Organisation des Soci étés Supérieures e La Contribution de Montesquieu a la Constitution de la Science Sociale, esta última escrita em latim -, e ainda Les Règles de la Méthode Sociologique, de 1895, conjunto de uma série de artigos aparecidos no ano anterior e que saiu como livro com ligeiras modificações e prefácio. Como escreve Mitchel (1973), Dela Division du Travail Social é um título desorientador, porque, embora trate da divisão do trabalho e tente dar uma explicação sobre o tema, o que fundamentalmente interessa ao autor é encontrar uma explicação para a solidariedade social na sociedade moderna. Procura caracterizar os dois tipos ideais de solidariedade: a mecânica, encontrada nas sociedades menos desenvolvidas, e a orgânica, típi- ca das sociedades industriais, onde predomina a divisão de trabalho. Como Durkheim irá assinalar no prefácio da segunda edição deste livro, de 1902, o principal motivo que este trabal ho levanta é aquele das relações entre a personalidade individual e a solidariedade social. Pergunta o sociólogo: "O que explica o fato que, na medida em que se torna mais autônomo, o indivíduo torna-se mais intimamente dependente da sociedade? Como pode ele ser pessoal mente mais desenvol vido e ao mesmo tempo mais socialmente dependente?" (Durkheim, 1902, apud Lukes, 1977:139). Esta era uma pergunta que Durkheim já havia formulado em seu primeiro curso, ministrado em 1887-1888, intitulado Solidariedade Social, no qual questionava a natureza da própria solidariedade social ao perguntar "quais são as frontei ras que unem os homens uns aos outros?". Lukes (1977:139) lembra que este problema permaneceu central na obra de Durkheim durante toda a sua vida, citando, inclusive, que em carta que escreveu a Bouglé, o sociólogo afirmava: o "objeto da soci ologia como um todo é determinar as condições para a conservação das sociedades". Não constitui objeto deste trabalho avançar na análise da questão da solidariedade social, mas situá-la como fundamental no pensamento de Durkheim presente em seu estudo sobre o suicídio. De outro lado, cumpre assinalar que o período que antecede a investigação sobre o suicídio foi extremamente original do ponto de vista metodológico. Assim, além dos trabalhos citados anteriormente, Durkheim escreve, em 1896, um artigo sobre a proibição do incesto e suas origens, aplicando à sociologia o método de análise de dados etnográficos, lançando no estudo sobre o suicídio a aplicação do método estatístico. É claro que a importância deste trabaIho, considerado "uma monografia exemplar" (Rodrigues, 1978:24), "um dosmelhores exemplos da 'teoria de médio al cance' " (Merton, 1968:63), "um modelo de pesqui sa social" (Selvin, 1958, apud Rodrigues, 1978:24), não se limita à aplicação do método estatístico. Por outro lado, é preciso saber no que a teoria sobre o suicídio é incompleta, pois, no dizer de Lukes (1977), esta é a mais fundamental e frutífera crítica ao trabalho de Durkheim.

A obra é constituída das seguintes partes: introdução, onde se situa a necessidade de constituir o objeto de estudo, definindo objetivamente o que é suicídio, a fim de pesquisar apenas as condições que virão constituir o fato determinado que o autor chama de "taxa social dos suicídios" e não todas as condições que possam ser contadas na gênese dos suicídios particulares; primeira parte - os fatores extra- 
sociais; segunda parte - causas sociais e tipos sociais; terceira parte - o suicídio como fenômeno social em geral.

Durkheim inicia o seu extenso trabalho pela discussão e delimitação do conceito de suicídio: "Chama-se suicídio todo o caso de morte que resulte di reta ou indiretamente de um ato positivo ou negativo, praticado pela própria vítima, sabedora de que devia produzir esseresultado" (Durkheim, 1982:16). Não se confunde com a tentativa, que seria "o ato assim definido, mas interrompido antes de resultar em morte" (Durkheim, 1982:16). Somente é possível quando se tem uma representação antecipada da morte, excluindo, portanto, nesse trabalho, tudo que diz respeito ao suicídio entre animais. Logo em seguida, passa a considerar por que o suicídio torna-se objeto de interesse para o sociólogo, perguntando: "Consi derando que o suicídi o é um ato da pessoa e que só a el a atinge, tudo indica que deva depender exclusi vamente de fatores individuais e que sua explicação, por conseguinte, caiba tão somente à psi cologia". Continua: “De fato, não é pel o temperamento do suicida, por seu caráter, por seus antecedentes, pel os fatos de sua história privada que em geral se explica a sua decisão?" (Durkheim, 1982:17-18). Não sendo este o enfoque a ser dado ao estudo, explica que "seem lugar devermos no suicídio apenas eventos particulares, isol ados uns dos outros e que exijam, cada um deles, exameem separado, consi derarmoso conjunto dos suicídi os cometi dos em dada sociedade durante um dado espaço de tempo, iremos verificar que o total assim obti do não éa simples soma de unidades independentes, um todo de coleção, mas que constitui por si mesmo um fato que énovo e sui generis, com unidadeeindividualidade, epois com sua natureza própria, eque, além disso, essa natureza é eminentemente social" (Durkheim, 1982:18). Ao levantar dados sobre a França, Prússia, Inglaterra, Saxônia, Baviera, Dinamarca, de 1841 a 1872, o autor afirma que "para uma mesma sociedade, desde que a observação se restrinja a um período não muito extenso, essa cifra é quase invariável" (Durkheim, 1982:18). Às variações, Durkheim associa alguma crise que atinge passageiramente o estado social, como, por exemplo, o que se deu no ano de 1848. Nesta data ocorre uma brusca diminuição em todos os estados europeus. Em interval os mais longos de tempo, verifica-se que ocorrem mudanças mais graves, que são bruscas e paulatinas, no sentido de que as taxas elevam-se, afirmam-se, acentuam-se e por fim estabilizam-se. Neste primeiro momento do seu trabalho, Durkheim afirma: “Cada sociedadetem, portanto, em cada momento de sua história, uma predisposição definida para o suicídio. Mede-sea intensidade relativa dessa tendência tomando-se a relação entre o número global por mortes voluntáriase a população de todas as idades e de ambos os sexos. Designaremos esse dado numérico por taxa de mortalidade-suicídio peculiar à sociedade consi derada. É cal culada, em geral, proporcionalmentea um milhão ou a cem mil habitantes" (Durkheim, 1982:19).

Para o autor, a taxa de suicídios constitui "uma ordem de fatos una e determinada; é o quesua permanência evariabilidade, si multaneamente, demonstram". Por intermédio dessa taxa expressa-se uma tendência e, seja qual for o juízo sobre o assunto, o fato é que "cada sociedade está predisposta a fornecer um contingente determinado de mortes voluntárias". De forma clara, expõe o objetivo do trabalho: "Nosso intuito não é, pois, o defazer o rol mais completo possível detodas as condições que possam contar na gênese dos suicídios particulares, mas pesquisar apenas aquel as que virão a constituir o fato determinado que chamamos de taxa social desuicídios". Fixa, então, como irá encarar o assunto: “O fenômeno por explicar só pode ser atribuído a causas extra-sociais de grande generalidade ou a causas propriamente sociais" (Durkheim, 1982:23).

Toda a primeira parte do estudo é dedicada aos fatores extra-sociais, dentre os quais inclui loucura, raça, hereditariedade, clima, temperatura, sazonalidade e a imitação. Em vista de muitas afirmações vigentes em sua época sobre a relação loucura-suicídio, Durkheim desmonta esta relação, mas, antes, desenvolve uma classificação de suicídios cometidos por loucos, ou seja, "para saber se o suicídi o é um ato próprio dos psi copatas, impõem-se determinar as formas que ele assumena alienação mental e ver depois se os psicopatas são os únicosa quem el eafeta" (Durkheim, 1982:30). Durkheim irá se referir aos tipos de suicídio maníaco, melancólico, obsessivo, impulsivo e automático e a sua conclusão é que não existe nenhum estado psicopático que mantenha com o suicídio uma relação regular e incontestável. Da mesma forma, não encontra relação com os estados psicológicos normais, raça e hereditariedade, nem com fatores cósmicos e imitação.

No Livro II, Durkheim irá tratar das causas sociais e tipos sociais, dividindo o tema nas seguintes partes: método para determinar as causas e os tipos sociais; os diversos tipos de suicídio: egoísta, altruísta e anômico; conclusão, com uma classificação morfológica sobre as formas individuais dos diferentes tipos de suicídio. 
Em realidade, esta parte do estudo de Durkheim constitui o cerne da sua proposta, que fica claramente definida quando afirma, tendo por base a análise até então empreendida, que: "Concluímos, defato, que existe, para cada grupo social, uma tendência específica ao suicídio que nem a constituição orgâni co-psíquica dos indivíduos nem a natureza do ambiente natural explicam. Resulta disso, por eliminação, que essa tendência deve depender de causas sociais e constituir por si mesma um fenômeno col etivo; inclusi ve, certos fatos que exami namos, sobretudo as variações geográficas e periódicas do suicídio, nos levaram expressamente a essa conclusão" (Durkheim, 1982:106). Ao optar por uma classificação etiológica do suicídio, o autor diz ser impossível uma classificação segundo as suas formas ou características morfológicas, pois haveria necessidade de um grande número de casos particulares.

Assim, parte para uma construção metodológica na qual "podemos constituir os ti pos sociais do suicídio, não ao classificá-los diretamente segundo as suas característi cas de antemão descritas, mas classificando as causas que os produzem" (Durkheim, 1982:107). Buscamse as condições sociais de que dependem, que são depois grupadas, conforme as semelhanças e diferenças. Dessa forma, o fenômeno será conhecido através de suas causas e não apenas de suas características, ou seja, como diz Durkheim, em uma construção de caráter etiológico. De outro lado, é importante destacar que, para Durkheim (1982:108-109), se quisermos entender o suicídio como fenômeno coletivo, "teremos de encará-lo desde o início sob a forma col eti va, isto é, através de dados estatísticos. A taxa social éo que temos de tomar di retamente por objeto deanálise; é preciso ir do todo às partes". Sua recomendação, ao final desta colocação metodológica, é a seguinte: "Para isso, deixando delado, por assim dizer, o indivíduo enquanto indivíduo, seus motivos e suas idéias, indagaremos i mediatamente quais são os estados dos diferentes mei os sociais (credos religiosos, família, sociedade política, grupos profissionais etc.), em função dos quais o suicídio varia. Só depois, voltando aos indivíduos, estudaremos de que modo essas causas gerais se individualizam para produzir os efei tos homicidas por elasimplicados" (Durkheim, 1982:112).

Volta-se, então, o autor, para analisar os três tipos de suicídio que constituem o ponto central de sua pesquisa.

Na primeira parte, analisa o que denomina de suicídio egoísta, estabelecendo três pressupostos: O suicídio varia na razão inversa do grau de integração da sociedade religiosa. 0 suicídio varia na razão inversa do grau de integração da sociedade doméstica. O suicídio varia na razão inversa do grau de integração da sociedade política. Para tal, estuda as informações referentes ao número de suicídios entre os estados protestantes, mistos (católicos e protestantes), católicos, católicos gregos, concluindo que "em toda parte, sem exceção, há muito mais sui cídi os entre os protestantes do que entre os adeptos dos demais credos" (Durkheim, 1982:115). Acrescenta que não adianta invocar a excepcionalidade da Noruega e Suécia, que apresentam um número moderado de suicídios. Explica que há diferenças entre as populações da península escandinava e a Europa Central e que as taxas de suicídio são baixas nesses países. No caso dos judeus, a taxa é menor do que a dos protestantes, mas ainda é inferior à dos católicos. Para Durkheim, o fato de serem populações mais intelectualizadas e viverem nas cidades seria a razão de terem maior inclinação ao suicídio do que os participantes de outras religiões e, assim, ficarem al heios à religião que praticam. Porém, conservam, em vista de todas as outras religiões, as mais baixas taxas. Lembra o autor que tanto o catolicismo, quanto o judaísmo são extremamente severos em relação ao suicídio, e que a única diferença essencial entre catolicismo e protestantismo é que este admite o livre exame das escrituras em grau muito maior. Escreve: “... o protestantismo participa mais na elaboração da sua crença (...). Chegamos pois a um primeiro resultado: a propensão do protestantismo pelo suicídi o deve estar em relação com o espírito de livre exame que anima esta religião" (Durkheim, 1982:119). Este livre exame é efeito de outra causa: o abalo das crenças tradicionais, que tem como conseqüência a possibilidade de se multiplicarem as cisões. Desta forma, conclui-se que o maior número de suicídios no protestantismo decorre do fato de que esta é uma religião menos fortemente integrada do que a católica.

É interessante a associação feita por Durkheim (1982:122) entre o livre exame e o gosto pela cultura. "A ciência, de fato, é o úni co meio de que dispõea livre refl exão para atingir seus fins. Quando crenças ou práticas irracionais perdem a sua autoridade, para encontrar outras impõe-se apelar para a consci ência esclareci da cuja forma superior éa ciência." Pelas suas informações, os protestantes são mais instruídos e se suicidam mais e restaria responder a questão: “Será certo que a necessi dade de instrução, na medida em que corresponde a um enfraquecimento da fé comum, aumenta como o suicídio?" (Durkheim, 1982:124). Junta a esta ques- 
tão uma análise das profissões liberais - onde se nutre o gosto pela ciência ea vida intelectual é mais intensa. Constata que maior grau de instrução e maior número de suicídios mantêm relação, como, também, ocorre em maior número entre homens do que entre mulheres: “Ora”, como escreve Durkheim (1982:126), "ela étambém muito menos instruída". Sua conclusão é de que o suicídio aumenta com o progresso da ciência, mas “não éa ciência que de termina este aumento. Ela é inocente e nada seria mais injusto que acusá-la; o caso dos judeus é demonstrativo disso". Neste caso "o homem procura instruir-see se mata porque a sociedade religiosa de que é membro perdeu coesão; mas não se mata porque é instruído" (Durkheim, 1982:128).

Uma outra conclusão desta parte é sobre a função profilática da religião sobre o suicídio. Neste aspecto, sintetiza a questão da seguinte maneira: "A influência benfazeja da religião não se deve, pois, à natureza específica das concepções religiosas. Se ela protege o homem contra o desejo de se destruir, não é porque lhe pregue, com argumentos peculiares, o respeito por sua pessoa, mas porqueéuma sociedade". Explica, também, que "o que constitui essa sociedade éa existência de certo número de crenças e de práticas comuns a todos os fiéis, crenças que são tradicionais e, por conseguinte, obrigatórias" (Durkheim, 1982:129).

Na parte seguinte, Durkheim trata de outros dois aspectos relacionados ao suicídio: a vida da família e a sociedade política.

Constata que os celibatários se matam menos que os casados e procura confrontar esta observação de que o casamento e a vida familiar aumentam a probabilidade de suicídio. Correlaciona as taxas para cada idade, comparando, por exemplo, os celibatários, os casados e os viúvos de 25 a trinta anos de idade, somente quando possível obterem-se tais informações, pois, de um modo geral, as publicações oficiais não fornecem esses dados. Nesse momento, Durkheim criou o que denominou coeficiente de preservação - número que indica quantas vezes menos as pessoas se suicidam num grupo em comparação com outro considerado na mesma faixa etária. Foi baseado nessas constatações que desenvolveu quatro leis: 1) Os casamentos muito precoces têm uma influência agravante sobre os suicídios, sobretudo no que se refere aos homens. 2) A partir dos vinte anos, os cônjuges dos dois sexos se beneficiam de um coeficiente de preservação em relação aos celibatários. 3) O coeficiente de preservação dos casados em relação aos celibatários varia com os sexos. 4) A viuvez diminui o coeficiente dos cônjuges dos dois sexos, porém, o mais das vezes, não o suprime completamente.

Para explicar essas leis, Durkheim (1982: 143) lança mão do seguinte argumento: a imunidade ao suicídio que as pessoas casadas desfrutam deve-se ou à influência do meio doméstico, ou ao que se pode chamar seleção matrimonial. A sua conclusão é que "a imunidade dos casados em geral se deveà influência da sociedade familiar, mas não à da soci edade conjugal, que ben eficia inteiramente os homens, e só em parte as mulheres".

O terceiro aspecto analisado por Durkheim nesta parte de seu estudo é referente à relação entre suicídio e sociedade. Revendo casos históricos, observa que o suicídio surge quando a velha organização da comunidade é abalada, por exemplo, Grécia e Roma, e mesmo na França, nas vésperas da Revolução. Ao citar uma investigação de Morseli sobre o fato de que no momento das grandes comoções políticas não ocorre aumento de suicídios, Durkheim mostra, mediante dados, que na França, em vários momentos, e mesmo em outros países da Europa, especialmente em 1848-1849, quando a crise é geral, em toda a parte diminuem os suicídios. Para Durkheim (1982:161), nem todas as crises políticas ou sociais influem sobre as taxas de suicídio, mas "só influem as que excitam as paixões". No final, explica: “Não éà crise que se deve a salutar influência (...), mas às lutas causadas pela crise. Forçando os homens a se unirem para enfrentar o perigo comum, o indivíduo pensa menos em si mesmo e muito mais na coisa comum. Compreen de se, de resto, que essa integração possa não ser meramente momentânea, mas sobreviva às vezes às causas que a suscitaram imediatamente, sobretudo, quando é intensa". Ao retomar os três aspectos tratados, o autor chega à conclusão geral de que "o suicídio varia na razão inversa do grau deintegração dos grupos sociais a que pertence o indivíduo". Irá também caracterizar o papel do egoísmo como origem do suicídio. Declara: "Quanto mais se enfraqueçam os grupos sociais a que ele (indivíduo) pertence, menos ele dependerá deles, ecada vez mais, por conseguinte, dependerá apenas de si mesmo para reconhecer como regras de conduta tão-somente as que se calquem nos seus interesses particulares. Se, pois, concordarmos em chamar de egoísmo essa situação em que o eu individual se afirma com excesso diante do eu social eem detrimento deste último, podemos designar de egoísta o tipo particular de suicídi o que resulta de uma individuação descomedida" (Durkheim, 1982:162). Ao enfatizar a força do individualismo, não 
apenas por favorecer a atuação de causas suicidógenas, mas por ser por si mesmo uma causa desse gênero, Durkheim (1982:167) apresenta dois pontos finais quanto ao suicídio egoísta. O primeiro é que às sociedades "inferiores" (sic) este tipo de suicídio é mais ou menos totalmente estranho, e o segundo é que causa um impacto menor sobre a mulher, no caso a solteirona ou viúva, que por terem uma "sensibilidade antes rudimentar do que muito desenvolvida" e por viverem "mais que o homem fora da vida comunal, esta vida exerce menor influência sobre la: a sociedade lheé menos necessária porque el a é menos impregnada de sociabilidade".

No capítulo que trata do suicídio altruísta, Durkheim (1982:168) afirma inicialmente: “Se, como acabamos de ver, uma indi vi duação excessiva leva ao suicídio, a individuação insuficiente produz os mesmos efeitos. Quando desligado da sociedade, o homem se mata facilmente, e se mata também quando está por demais integrado nela". Para o autor, este tipo de suicídio é endêmico em sociedades inferiores, e depois de exemplificar com casos históricos, classifica-os em três categorias: 1) suicídios de pessoas que chegaram ao limiar da velhice ou adoeceram; 2) suicídios de mulheres por ocasião da morte do marido; 3) suicídios de clientes ou servidores ao ensejo da morte dos seus chefes. Esclarece que há o suicídio altruísta obrigatório, como há o facultativo, e, ainda, o suicídio altruísta agudo, do qual o suicídio místico é o melhor exemplo. Se estes casos caracterizam as sociedades primitivas, no dizer de Durkheim, eles aparecem nas estatísticas utilizadas quando o autor verifica o aumento dos suicídios no exército: os militares se suicidam um pouco mais do que os civis da mesma idade e de iguais condições. A hipótese é que muitas causas levariam a crer que a vida militar deveria preservar do suicídio - são pessoas selecionadas rigorosamente do ponto de vista da saúde e pertencem a um grupo com alto esprit decorps. Portanto, não podem ser explicados como pertencentes ao tipo egoísta, e sim do tipo caracterizado por "uma fraca individuação ou do que designamos por altruísmo" (Durkheim, 1982:183). O terceiro tipo de suicídio estudado por Durkheim é o anômico. Como em toda a sua pesquisa, o autor inicia apresentando uma série de dados. Os primeiros dizem respeito às relações crise ou crescimento econômico e propensão ao suicídio.

Conclui o autor que tanto as crises industriais ou financeiras, como as de prosperidade, têm o mesmo resultado: aumentam os suicídios, e explica dizendo que esta relação se dá porque são crises, isto é, "perturbações da ordem coletiva" (Durkheim, 1982:193). Na argumentação de Durkheim, quando das crises econômicas ocorre como um déclassement, e os indivíduos atingidos passam para uma situação inferior à até então ocupada, impondoIhes uma série de restrições e "todos os frutos da ação social ficam perdidos no que se refere a eles: têm de refazer a sua educação moral" (Durkheim, 1982:199). Sendo este um processo não imediato, leva os indivíduos a não se ajustarem às novas condições. O mesmo se aplica se a crise é motivada por um brusco aumento de poder e riqueza, despertando todo tipo de cobiça, no "exato momento em que as normas tradicionais perderam a sua autoridade. O estado de desregramento ou de anomia é pois reforçado pelo fato de que as paixões estão menos disciplinadas no preciso momento em que teriam necessidade de uma disciplina mais rígida" (Durkheim, 1982:200). Para Durkheim, as atividades industriais e comerciais são as que registram mais suicídios, estando quase no mesmo nível que as carreiras liberais, ao passo que as taxas são mais baixas na agricultura. Comparando patrões e empregados, afirma serem os primeiros mais atingidos que estes últimos. Após estes exemplos, situa a anomia como sendo um fator regular e específico de suicídios nas sociedades modernas, sendo diferente dos outros tipos, pois "depende não do modo como os indi víduos estão presos à sociedade, mas da maneira como esta os rege". O suicídio anômico "decorre de que as ativi dades dos homens estão desregradas e que isto os faz sofrerem" (Durkheim, 1982:204).

Volta-se, então, para analisar os suicídios que ocorrem quando da viuvez, tema já tratado anteriormente. Neste ponto explica que a causa deve-se à anomia doméstica. Estuda também o suicídio entre divorciados, que se matam entre três a quatro vezes mais que os casados e nitidamente mais que os viúvos. Para Durkheim, é o estado de anomia conjugal, produzido pela instituição do divórcio, que explica o desenvolvimento paralelo dos divórcios e dos suicídios. Como diz, não pretende afirmar que o afrouxamento das relações conjugais seja exclusivamente devido ao estabelecimento legal do divórcio, pois a anomia matrimonial pode existir na opinião pública sem estar ainda consignada na lei.

No capítulo seguinte, analisa as "Formas individuais dos diferentes tipos de suicídios" (Durkheim, 1982:222-236). Coloca em evidência que os tipos sociais que propõe correspondem aproximadamente a tipos psicológicos. Assim, ao suicídio egoísta corresponde apatia e 
secundariamente melancolia; ao altruísta, energia passional ou voluntária e sentimento do dever; ao anômico, corresponde irritação, desgosto e como variedade secundária, queixas contra a vida etc. Há, ainda, a possibilidade de tipos mistos combinando os três tipos elementares.

No capítulo em que estuda "O el emento social do suicídio", Durkheim (1982:237-259) tece considerações para reforçar a sua posição de que "de todos os fatos por nós estudados resulta que a taxa social dos sui cídi os só se explica sociologi camente". Ao prosseguir nesta afirmação, diz: "É a constituição moral da sociedade que determina a cada instante o contingente das mortes voluntárias. Existe, pois, para cada povo, uma força coletiva, de determinada energia, que impele os homens a se matarem". Reafirma também, em relação às condições individuais, que: "Os movimentos queo pacienterealiza, e que, à primeira vista, parecem só exprimir o seu temperamento pessoal, são, em realidade, a conseqüência e o prolongamento de um estado social que manifestam exteriormente". A constância da taxa social seria suficiente para demonstrar a exatidão da afirmação e mais uma vez volta a afirmar que "a causa geradora do fenômeno escapa forçosamente a quem só observa casos i solados, pois é exterior aos indivíduos. Para descobri-la é preciso colocar-seacima dos suicídios isolados e enxergar o quel hes dá unidade".

Dois outros aspectos são discutidos por Durkheim quando estabelece as relações do suicídio com outros fenômenos sociais: se deve ser classificado entre os atos permitidos pela moral e suas relações com os crimes e outras contravenções penais. Segundo o autor, o suicídio é classificado entre os atos imorais e deve ser reprovado. Entre os diversos pontos apresentados por Durkheim na relação suicídios e homicídios, destaca que, embora sob alguns pontos estes dois fenômenos estejam em concordância, há claros contrastes entre eles. Enquanto na França, Prússia e Itália aumentam os suicídios, diminuem os homicídios, e a intensidade máxima dos dois eventos não ocorre no mesmo ponto do tempo; o suicídio é muito mais urbano que rural, ao passo que o contrário se dá com o homicídio; são os homicídios muito mais freqüentes nos países católicos que nos protestantes. Para Durkheim, as contradições encontradas entre os dois eventos deve-se a existirem diferentes tipos de suicídio, dos quais alguns mantêm certo parentesco com o homicídio e outros, não.

Durkheim (1982:289-314) finaliza o seu livro com um capítulo intitulado "Conseqüências práticas". Para ele, o suicídio havia se transformado em "um fenômeno patológico quesetorna cada vez mais ameaçador". Pergunta, então, como afastá-lo. Mediante penas cominatórias? Certamente que não, pois “não será graças a dispositivos legais que se há de despertar a nossa sensi bilidade moral". Pergunta, também, sobre o papel da educação, como meio de assegurar o fortalecimento da moral e, conseqüentemente, conter o fenômeno, ou, como queriam alguns, desenvolvendo convicções. Para ele, isto levaria a atribuir à educação um poder que ela não possui. Também não se poderia buscar na sociedade política e mesmo na sociedade religiosa a função de "lembrar permanentemente ao homem esse salutar sentimento de solidariedade", através do qual a vida readquiriria sentido e Ihe daria maior proteção. Pergunta, ainda, se a profilaxia contra o suicídio não poderia se dar pela família. Responde: “Mas seria ilusão acreditar que bastará di minuir o número de celibatários para conter o avanço do suicídio". Para Durkheim, “além da sociedade confessi onal, familiar, política, uma outra há de que até agora não tratamos: tratase daquela constituída pela associação de todos os trabal hadores da mesma categoria, todos os cooperadores da mesma função, o grupo profissional ou a corporação". Além de ver a atividade profissional como o núcleo fundamental - é permanente, existe em todos os lugares e exerce sua força pela maior parte da existência - , de onde podem emanar os novos valores, e a cooperação como necessária à crescente divisão do trabalho, Durkheim acredita que a restruturação dos grupamentos locais e a "descentralização profissional", que multiplicaria os centros de vida comum, sem romper a unidade nacional, poderiam deter o avanço do suicídio contemporâneo, do mal-estar de que padece a própria sociedade.

\section{Comentários}

Tendo rejeitado os argumentos extra-sociais que teriam alguma influência sobre o suicídio, as disposições orgânico-psíquicas, internas aos indivíduos, tanto normais, como anormais, as características do ambiente físico, e o processo de imitação, Durkheim, por meio da combinação da prova estatística e argumento dialético, vai procurar comprovar as suas hipóteses. Lukes (1977:205) assinala que a explicação de Durkheim foi "realmenteuma tentativa de responder a questão: que relações expli cativas existem entre as formas de vida social e os atos individuais de abandoná-la?". No comen- 
tário deste autor, embora a tentativa não tenha sido coroada de completo êxito, a teoria de Durkheim tem tido uma imensa influência no que se refere à teoria sociológica específica sobre o suicídio. Ao citar Giddens (1981), cujas críticas ao trabalho de Durkheim, na década de 60 , são bastante contundentes, lembra que pouco se avançou na teoria sobre o suicídio após O Suicídio, mesmo porque as explicações dadas, posteriormente, são formuladas de maneira menos precisa, não oferecendo maior contribuição à sua teoria.

Voltando ao texto de Giddens (1981), vejamos quais os pontos críticos considerados por esse autor. Em primeiro lugar, avalia que a análise de Durkheim não demonstra que os fatos não sociais não influem sobre as taxas de suicídio, ou que, agindo de forma combinada, não possam vir a ter influência sobre o suicídio; a única constatação é a de que esses fenômenos não sociais não explicam as diferenças nas referidas taxas. Outro ponto é a demasiada confiança de Durkheim nas estatísticas oficiais, como medida exata da distribuição do suicídio. Para Giddens, mesmo as diferenças encontradas entre diferentes regiões de um único país podem resultar das divergências na avaliação da prova do suicídio. O autor vai buscar nos argumentos apresentados por Douglas (1970) a validação das suas críticas, quando afirma: “Uma taxa de suicídio é mais que um índi ce de incidência de atos deautodestrui ção. É um fato social em si mesmo; conseqüência de um conjunto complexo de eventos que envolvem numerosos atores sociais: parentes, amigos, médicos, polícia, magistrados, encarregados de investigar casos de mortesuspeita, etc." (Giddens, 1981:87). Cita, ainda, o fato de Durkheim não ter se preocupado em estudar as tentativas de suicídio, que, para Giddens, são fundamentais para compreender os atos suicidas consumados.

Do ponto de vista da construção teórica, os autores apontam que, em essência, Durkheim estava interessado em especificar teoricamente três tipos de causa social - egoísmo, altruísmo e anomia -, cada tipo representando um conjunto de fatores associados, relacionandoos com al tas ou ascendentes taxas de suicídio (Lukes, 1977). O esquema teórico de referência da qual deriva esta tipologia relacionava-se à concepção durkheimiana de moralidade e solidariedade social. É de fundamental importância, como foi visto na síntese do seu trabalho, que para ele o suicídio era a antítese da solidariedade. Esclareça-se, também, que os tipos de suicídios foram usados pelo autor para distinguir distintas correntes suicidógenas. No comentário de Aron (1982), estas correntes que atravessam a sociedade, originando-se não no indivíduo, mas na coletividade, são a causa real e determinante do suicídio. Prossegue Aron (1982:315), retomando uma idéia central do trabalho de Durkheim: "As causas reais dos suicídi os são, em suma, forças sociais que variam desociedade para sociedade, de grupo para grupo e dereligião para religião. Emanam do grupo enão dos indivíduos i soladamente".

Dentre os estudos críticos, deve-se citar o de Ritzer \& Bell (1981), que submetem a obra de Durkheim a uma interrogação: seria ela o exemplo de um paradigma sociológico integrado? A resposta é que, embora tenha tratado praticamente de todos os níveis da realidade social, mesmo considerando alguns de maneira muito fraca, o problema básico do ponto de vista de um paradigma integrado é a irregularidade. Acrescentam a essa crítica o seguinte: “Uma outra fraqueza éa fal ta de uma dialética; ou um model o de sistema; há grande interesse no impacto das macroestruturas sobre os fenômenos de nível micro, mas os efeitos realimentadores são largamente ignorados" (Ritzer \& Bell, 1981:989).

Um outro comentário que se torna necessário é o referente à distribuição dos suicídios. Segundo os dados da pesquisa de Durkheim, para a França, Prússia, Inglaterra, Saxônia, Baviera e Dinamarca, as taxas médias de suicídios por cem mil habitantes eram as seguintes: de 1841 a 1846 - 8,5; de 1849 a 1855 - 10,1 e de 1856 a 1860 - 11,2. Isto não somente demonstra uma taxa constante durante longos lapsos de tempo, como também permite verificar que se apresentava com menor variabilidade do que outros fenômenos demográficos, por exemplo a mortalidade geral. Durkheim constatou que no decurso de três períodos: 18661870, 1871-1875 e 1874-1878, não só ocorreu o aumento do suicídio em todos os países, como também conservaram os seus coeficientes de aceleração. Para a França, as taxas nesses períodos foram as seguintes: 13,5; 15,0 e 16,0 por cem mil habitantes. Atualizando os dados, para a França, a cada cem mil habitantes, entre 1950-1976, a taxa foi de 15 e, em 1993, 21, conforme Philippe (1993). Segundo dados recentes da World Health Organization (WHO, 1994), em 1993, a taxa média anual mundial de suicídios era de oito por cem mil habitantes, porém a sua distribuição entre os países era bastante variável: Hungria: 38,6; Sri Lanka: 35,8; Finlândia: 29,8; Suíça: 22,7, que apresentam as taxas mais elevadas, e países como o Brasil, com cerca de quatro suicídios por cem mil habitantes. Voltando aos dados referentes à França, verifica-se que a mortalidade por suicídios não so- 
mente cresceu, como modificou a sua distribuição, no que se refere às categorias sócioprofissionais. Tanto os dados levantados por Durkheim, como por Halbawachs, mostram que, na segunda metade do século XIX, as taxas eram maiores para as carreiras liberais. Durkheim (1982) encontra na França, de 18781887, a cifra de trezentos suicídios por milhão de pessoas de cada profissão; Halbawachs (1930), para o período de 1861-1865, entre os liberais e os que vivem de renda, encontra o valor de 389. Este autor cita que, entre as profissões agrícolas, o número era de 131 e, entre as industriais e comerciais, 196. Todd (1981:55), ao retomar as estatísticas dos suicídios profissionais, afirma que: "No curso do século que precedea guerra de 1914-1918 não éa mi séria material que provoca o desespero absoluto. Não se pode explicar simplesmente o crescimento ge ral da freqüência do suicídio pelos padrões da vida econômica". Como este autor irá analisar, na segunda metade do século XX ocorre profunda modificação, o coeficiente de mortalidade por suicídio, por cem mil homens de 45 a 54 anos, de 1966-1971, era de 18,7 para os pertencentes aos quadros superiores e profissionais liberais; 49,3 para os operários especializados; para os agricultores proprietários, 72,2; para os trabalhadores manuais, 93,7; para os assalariados agrícolas, 98,1. Corroborando esta situação, Philippe (1993:10), do Institut National de la Santé et de la Recherche M édicale, dizia que o suicídio é atualmente "um mal mais freqüente nos meios rurais e populares que entre os privilegiados. Defato, observa-sequeo risco desuicídi o mantém-se paralel o ao das mortes em geral: um operário vivemenos que um membro de outras profissões".

Há cem anos, Durkheim escreveu um trabalho que, no dizer de Aron (1982:308) "tem o rigor de uma dissertação acadêmica. Começa por definir o fenômeno; continua com uma refutação das interpretações anteriores; estabelece uma tipologia; e, com base nessa tipologia, de senvolve uma teoria geral do fenômeno considerado". Nesse sentido, é exemplar. Não precisamos citar as suas Regras do Método Soci ológico (Durkheim, 1960), pois elas são evidentes neste trabalho. Tanto assim, que é em outro trabalho de sua autoria - La Contribution de Montesquieu à la Constitution de la Science Sociale- que se pode buscar uma raiz importante para compreender a elaboração desta sua investigação. Nessa tese, ele afirma: "Interpretar as coisas, não émais do que dispor as idéias que nós possuímos, segundo uma ordem determina$d a$, que deve ser a mesma que a das coisas. $O$ que pressupõe que, nas próprias coisas, essa or- dem exista, isto é, que se descubra séries contínuas, cujos el ementos estejam ligados entre si detal maneira que um efeito sempre resulte da mesma causa enão possa provir de outra. Que se suponha, ao contrário, destruída a necessidade desse liame causal, os efeitos poderiam se produzir sem causa ou em seguida a uma causa qualquer, tudo se tornaria apenas caprichoso e fortuito; ora, o que é caprichoso não é suscetível deinterpretação" (Durkheim, 1953:88-89, apud Fernandes, 1959).

Ao transpor esta citação para o trabalho sobre o suicídio, reafirma-se que a preocupação básica de Durkheim era a construção metodológica. Nesse sentido, Fernandes (1959) considera que há três importantes contribuições metodológicas oferecidas por Durkheim. A primeira refere-se à seleção da base empírica; a segunda diz respeito à formação da inferência indutiva e a terceira refere-se à verificação da inferência indutiva. Esta constitui uma das maiores dificuldades da sociologia pela impossibilidade de realizar a experimentação propriamente dita, e Durkheim adotará como meio adequado para a ministração da prova o método das variações concomitantes. Segundo Fernandes (1959:88): "Talvez seja esse o ponto mais fraco de sua teoria da investigação sociológica".

Inegavelmente, a metodologia utilizada por Durkheim, apesar das críticas que se fazem à utilização das estatísticas, como já apontado, constitui um dos pontos altos do seu estudo. Porém, como salienta Aron (1982), algumas controvérsias levantaram-se em relação à validade das relações estabelecidas por Durkheim, como as tratadas por Hal bwachs (1930). Para Durkheim, os protestantes suicidam-se mais freqüentemente do que os católicos porque a força integrativa do catolicismo é maior do que a do protestantismo. Para Halbwachs, há a necessidade de verificar se os dois grupos religiosos vivem em zonas agrícolas ou em cidades e se têm modos de vida diferentes. Isto alteraria a força do valor integrativo das religiões. Douglas (1970:127), ao anal isar o estudo de Halbwachs, coloca em evidência que: "Eleacreditava que di ferenças nas rel ações famil iares, religião, ti pos de ocupação, grau de escolaridadee posi ção sócio-econômica eram todas meramente aspectos das di ferenças fundamentai s entre os modos de vida urbano e rural. E ele acreditava que era a diferença fundamental nas formas de vida urbana e rural que explicava muitas das diferenças na distribui ção social do suicídio". Halbwachs pôs este ponto em evidência quando mostrou que as taxas de suicídio decresciam quando se passava das áreas com populações mais densas e rel ativamente urbani- 
zadas para as menos populosas, rurais e montanhosas. Tem sido apontado que nem sempre é muito claro o significado de modo de vida. Em geral, segundo Douglas (1970), refere-se ao que hoje chamaríamos de cultura, ou seja, significados que são partilhados e transmitidos, mas não chegam, como no caso de Durkheim, a delinear tipos de representações coletivas, tais como egoísmo-altruísmo e anomia-fatalismo.

A questão do significado introduz a principal crítica feita por Douglas (1970) aos estudos sobre o suicídio, e a abordagem da hi pótese estatística, ou abordagem positivista, levou-o a elaborar uma abordagem teórica das ações suicidas como ações sociais. Defende que o importante é distinguir os situated meanings dos abstract meanings, pois os primeiros são fundamentais para descrever formas de ação social, básicas para o estudo do suicídio. Como referido por Boudon \& Bourricaud (1993), a abordagem biográfica e qualitativa defendida por Douglas (1970) seria brilhantemente desenvolvida por Baechler (1975), para quem "pode-se interpretar o suicídi o como uma resposta a uma si tuação: todos os sui cídi os resultariam do fato de que o suicida deixou-se prender numa armadilha. O suicídio, portanto, deve ser interpretado como uma solução 'estratégi ca' dada pelo indivíduo a problemas existenciais" (Baechler, 1975, apud Boudon \& Bourricaud, 1993:551). Não se pode deixar de citar o trabaIho realizado por Besnard (1976), que procedeu à circunstanciada análise do livro de Baechler (1975), no qual se explicita um claro projeto antidurkheimiano, embora o exame crítico da obra de Durkhei m ocupe somente quatro páginas, num total de 650. Mas, como lembra Besnard (1976:314), esta análise de Baechler é "pontuada aqui e ali de sarcasmos contra as correntes suicidógenas ou outras interpretações 'pueris' ou 'cômi cas' de Durkheim”. Para Besnard (1976), embora seja necessário interrogar sobre a validade das estatísticas oficiais, não se podem aceitar sem controle os argumentos que conduziriam a renunciar a qualquer esforço para cercar o problema. Na mesma linha de argumento, Todd (1981:248) escreve: “Imperfejta, a taxa de suicídio é, na prática, muito superior em qualidade a outros indicadores sociais mais freqüentemente utilizados, como o produto nacional bruto per capita. Com efeito, é muito mais fácil dissimular a riqueza (numa declaração de renda) do que fazer desaparecer um cadáver. Não se pode, pois, colocar em questão o valor da 'taxa de suicídio' sem abandonar de um sal to toda uma gama de indicadores econômicos, desde a renda nacional per capita atéa taxa deinvestimentos".
Constantemente citado como exemplo de estudo epidemiológico, um dos pontos críticos apontados pelos epidemiologistas é que o uso de dados agregados provoca um erro metodológico denominado falácia ecológica, ou seja, a produção de inferências causais sobre comportamentos individuais com base em dados agregados ou grupais (Robinson, 1950; Selvin, 1958). Entre os estudos que procuraram mostrar o valor epidemiológico das estatísticas de suicídio, cite-se o de Sainsbury (1972). Nesse trabalho, o autor estudou as taxas de suicídio da Inglaterra e País de Gales, de 1901 a 1961, por sexo e grupos etários, assim como as taxas de um grupo de países, no período de 19211923 a 1952-1954, tendo, também, correlacionado as taxas de suicídio de imigrantes nos Estados Unidos com as taxas de seus países de origem. Neste caso, a correlação encontrada foi considerada altamente significante, tendo sido concluído que as diferenças que aparecem nas estatísticas entre os países não se devem a diferentes processos no relato das mortes. Ponto alto deste trabalho é o referente à possibilidade, de um lado, de utilizar as estatísticas no estudo epidemiológico do suicídio, discordando das afirmações de Douglas (1970), e, de outro, de evidenciar ser altamente produtivo para o estudo do suicídio a combinação da abordagem epidemiológica e do estudo de caso.

Por sua vez, os psiquiatras, quando analisam as relações entre suicídio e doença mental, não chegam a um consenso. Uma detalhada análise crítica sobre as fontes psiquiátricas utilizadas por Durkheim foi realizada por Berrios \& Mohanna (1990). O argumento apresentado por esses autores não é o de que Durkheim não tenha levado em conta os trabalhos dos alienistas, ou "negado quea desordem mental, significados e intenções fossem importantes particularmente para o suicídio 'egoísta', mas que ele estava enviesado na escolha desuas fontes psiquiátricas, e como conseqüência pintou um quadro distorcido da história das idéias psi quiátricas sobre o sui cídio no século XIX na França" (Berrios \& Mohanna, 1990:1). A idéia apontada pelos autores de que Durkheim teria sido seletivo e idiossincrático na escolha de seu material e terminologia é contestada por Lloyd (1990), quando, ao comentar o texto de Berrios \& Mohanna (1990), afirma que para o sociólogo francês havia, certamente, mais "o desejo positivista de estudar as taxas, as regras e ti pos do fenômeno social do que inquirir sobre (desconhecida) intencionalidadeindividual" (Lloyd, 1990:594). Nesta linha de crítica ao texto de Berrios \& Mohanna, Youssef (1990:750) também assinala que “Durkheim estava escrevendo 
uma teoria sociológica sobre o suicídio e não um texto psiquiátrico". Considerando-se as controvérsias que ainda existem em relação ao tema das relações doença mental/ suicídio, recorremos ao texto de Mello (1992:64), que ao fazer um recente levantamento bibliográfico sobre o assunto, aponta que "o número de autores que não admitem tomar o suicídi o isoladamente como critério de doença mental étão significativo quanto os de opiniões contrárias". Para Mello (1992:65), "na falta de um contexto sintomatológico que permi ta o diagnóstico psi quiátrico, não enquadraríamos o ato suicida, automaticamente, como patognômico de doença mental".

As questões sobre o suicídio, suas causas, fonte de dados, abordagens teóricas e metodológicas não se encerram com estes comentários. Trata-se, sem dúvida, de um tema que ultrapassa os limites de um único campo do conhecimento, mas, do ponto de vista sociológico, o texto de 1897 de Durkheim é um exemplo de integração de teoria e dados. Mesmo os seus

\section{Referências}

ARON, R., 1982. As Etapas do Pensamento Sociológico. São Paulo/Brasília: Martins Fontes/Ed. Universidade de Brasília.

BAECHLER, J., 1975. Les Suicides. Paris: Calman-Lévy. BERRIOS, G. E. \& MOHANNA, M., 1990. Durkheim and French psychiatric view a on suicide during the 19th century. British Journal of Psychiatry, 156:1-9.

BESNARD, P., 1976. Anti- ou anté-durkheimisme? Contribution au débat sur les statistiques officielle du suicide. Revue Française de Sociologie, 18:313339.

BOUDON, R. \& BOURRICAUD, F., 1993. Dicionário Crítico de Sociologia. São Paulo: Ática.

DOU GLAS, J. J., 1970. The Social Meanings of Suicide. New Jersey: Princeton University Press.

DURKHEIM, E., 1960. As Regras do Método Sociológico. São Paulo: Cia. Editora Nacional.

DURKHEIM, E., 1970. Suicide- A Study in Sociology. London: Rowtledge \& Kegan Paul.

DURKHEIM, E., 1982. O Suicídio - Um Estudo Sociológico. Rio de Janeiro: Zahar Editores.

FERNANDES, F., 1959. Fundamentos Empíricos da Explicação Sociológica. São Paulo: Cia. Editora Nacional.

GIDDENS, A., 1981. As Idéias deDurkheim. São Paulo: Editorial Cultrix.

HALBWACHS, M., 1930. Les Causes du Suicide. Paris: Felix Alcan.

LLOYD, K., 1990. Le suicide. British Journal of Psychiatry, 156:593-594.

LUKES, S., 1977. Émile Durkheim: His Life and Work A Historical and Critical Study. England: Penguin Books. críticos reconhecem a engenhosidade e o briIho com que realizou este trabalho. Symonds (1991), ao revisar o texto do sociólogo francês, não somente fala da sua relevância, como cita que recente busca na base de dados do Sociological Abstracts revelou que este trabalho é citado em 189 das 1.490 referências, e 1.485 vezes no total.

Por outro lado, os suicídios estão classificados entre as mortes por causas violentas, juntamente com os homicídios, acidentes e envenenamentos, tornando-se importante fenômeno para avaliar, juntamente com outras estatísticas vitais, a situação de bem-estar de uma sociedade, e como um problema de saúde. Novas metodologias e abordagens não retiram do trabalho de Durkheim o seu pioneirismo, que ainda suscita inúmeras possibilidades de análise para os pesquisadores sociologicamente orientados, os quais hoje contam com melhores estatísticas e com o desenvolvimento de análises quantitativas não existentes na época em que Durkheim realizou a sua pesquisa.

MELLO, M. F., 1992. O suicídio e a doença mental. Temas, 43:63-66.

MERTON, R. K., 1968. Social Theory and Social Structure. New York: Free Press.

MITCHELL, G. D., 1973. Historia de la Sociologia. Madrid: Ediciones Guadarrama.

PHILIPPE, A., 1993. C'est à 80 ans que l'on se tue le plus. LeNouvel Observateur, 1.489:10.

RITZER, G. \& BELL, R.., 1981. Émile Durkheim: exemplar for un integrated sociological paradigm. Social Forces, 59:966-995.

RODRIGUES, J. A., 1978. A sociologia de Durkheim In: Émile Durkheim: Sociologia (J. A. Rodrigues, org.), pp. 8-37, São Paulo: Ática.

ROBINSON, W. W., 1950. Ecological correlations and the behaviour of individuals. American Sociological Review, 15:351-357.

SAINSBURY, P., 1972. The social relations of suicide: the value of a combined epidemiological and case study approach. Social Science \& Medicine, 6:189-198.

SELVIN, C., 1958. Durkheim's Suicide and problems of empirical research. American Journal of Sociology, 63:607-619.

SYMONDS, R. L., 1991. Suicide. A study in sociology: Émile Durkheim. British Journal of Psychiatry, 159:739-741.

TODD, E., 1981. O Louco e o Proletário. São Paulo: Ibrasa.

WHO (World Health Organization), 1994. World Health Statistics Annual - 1993. Genève: WHO.

YOUSSEF, H., 1990. Durkeim's views on suicide. British Journal of Psychiatry, 156:750. 